\title{
SURVIVAL RATE, PERI-IMPLANT SOFT TISSUES AND CRESTAL BONE LOSS OF IMPLANTS INSERTED BY FLAP OR FLAPLESS SURGERY IN TYPE 2 CONTROLLED DIABETIC PATIENTS AND IMMEDIATELY LOADED WITH MANDIBULAR FIXED PROSTHESIS. ONE YEAR RANDOMIZED CLINICAL TRIAL
}

\author{
Hosam E. Said*
}

\begin{abstract}
Objectives: The aim of this short-term randomized trial was to evaluate survival rate, periimplant soft tissues and crestal bone loss of implants inserted by flap or flapless surgery in type 2 controlled diabetic patients and immediately loaded with mandibular fixed prosthesis

Materials and methods: Twelve completely edentulous patients with controlled type II diabetes mellitus (HbA1c ranged from 5 to $6 \%$ ) were randomly assigned into two equal groups: Group I (flap surgery) received 6 implants in the mandible using standardized full-thickness mucosal flap surgery and free hand implant placement; Group II (flapless surgery) received 6 implants in the mandible using flapless surgical approach and computer guided implant placement. Implants were immediately loaded with acrylic fixed restoration. Three months later, fixed ceramo- metal restoration was delivered. Implant survival rate, peri-implant soft tissues (plaque index, gingival index, pocket depth and keratinized mucosal width) and crestal bone loss were evaluated at time of implant loading (baseline), 3 months, 6 months and 12 months after loading.
\end{abstract}

Results: The implant survival rate was $94.5 \%$ and $91.6 \%$ in the flap and flapless groups respectively. Without difference between groups $(\mathrm{p}=.652)$. For both groups, plaque scores, pocket depth and crestal bone loss significantly increased with time. Gingival scores significantly increased from baseline to 3 months, then significantly decreased thereafter. Keratinized mucosal width significantly increased from baseline to 3 months for flap group and insignificantly decreased for flapless group. Flap group showed significant higher plaque scores, gingival scores, pocket depth, width of keratinized mucosa and crestal bone loss than flapless groups.

Conclusion: Computer guided flapless surgical approach may be recommended for implants placed in edentulous type 2 controlled diabetic patients and immediately loaded with mandibular fixed prosthesis as it was associated with favorable peri-implant soft tissue response and crestal bone loss compared to implants placed with flap surgery after one year.

* Lecturer of Oral and Maxillofacial Surgery Department, Faculty of Dentistry, Delta University, Egypt. 


\section{INTRODUCTION}

Diabetes Mellitus is a group of metabolic disorders characterized by an increase in plasma glucose levels ${ }^{1}$. There are mainly two types of diabetes: 1) type I diabetes (insulin-dependent) which characterized by a lack of insulin production and 2) type II diabetes (noninsulin dependent) which is caused by the body's ineffective use of insulin² Diabetic patients have several complications that may affect the healing potential following endosseous implant treatment such as microvascular disease, susceptibility for infection, and delayed wound healing ${ }^{3}$. Moreover the implants in these patients subjected to mechanical overload resulting from diabetes-induced lower percentage of boneto-implant contact, immature bone, and incorrectly formed bone ${ }^{4}$. Therefore, patients with diabetes were not considered suitable for implant treatment when the treatment was introduced. However, over the past 2 decades, diabetes has been regarded as a relative (not absolute) contraindication for implant therapy related to the stability of the diabetic's blood sugar level ${ }^{3}$. Measurements of glycated hemoglobin (HbAlc) levels is considered an accurate method to determine glycemic control in diabetic patients as it reflected the blood glucose level over the last 2-3 months ${ }^{5,6}$. Good glycemic control is essential to maintain the function of osteoblast and the decrease the rate of crestal bone loss ${ }^{7}$. Recommendations for strict glycemic control for persons with diabetes have targeted maximal $\mathrm{HbA} 1 \mathrm{c}$ levels ranging from $6.5 \%$ up to $7.0 \%{ }^{8,9}$ Implant success rate in patients with type II controlled diabetic patients was reported to range from 9 to $100 \%{ }^{10-12}$

The traditional used full-thickness flap surgical approach provides good visualization of anatomical structures, ridge shape and landmarks at implant placement which reduce the risk of bone fenestration and perforation but the technique is usually associated with increased postoperative pain, discomfort, bleeding and edema as well as increased marginal bone resorption ${ }^{13,14}$. In contrast, the flapless surgical approach is minimally invasive, is associated with reduced surgical trauma, short observation period, reduced postoperative pain, and swelling, increased patient satisfaction and rapid healing ${ }^{15,16}$. Moreover, it preserves blood supply to the periosteum of bone and decrease bone $\operatorname{loss}^{17}$. However, flapless surgical approach is a blind technique which may increase the risk of bone perforation, over or under preparation of implant osteotomy and inability to manipulate periimplant soft tissue to increase keratinized mucosal width $^{18,19}$.

Immediate loading of the implants by professional restoration achieves higher patient satisfaction as it provides immediate restoration of mastication and aesthetics without need to wear dentures during osteointegration. However, uncontrolled loading may induce micromotions at implant/bone interface and cause marginal bone loss ${ }^{20}$. Reviewing the literature, the effect of immediate loading on the success rate of implants inserted in patients with controlled type 2 diabetes was scare and limited to single implants installed in premolar and molar regions and supported single restorations ${ }^{21}$ or implants inserted in maxillary anterior region (esthetic zone $)^{5,7}$. However, evaluation of immediate loading of full arch fixed restoration in edentulous controlled diabetic patients was not a concern. Moreover, the effect of the surgical approach (flap Vs flapless) on clinical and radiographic outcomes of implants inserted in controlled type 2 diabetes was limited to delayed loading protocol only which was used either with full $\operatorname{arch}^{10}$ or single tooth ${ }^{22}$ prosthesis and immediate loading protocol was not evaluated. Furthermore, there is still little information in the literature regarding the implant survival and periimplant tissue outcomes of implants inserted with flapless surgery in controlled diabetic patients ${ }^{10}$.

Accordingly, the purpose of the present study was to evaluate the survival rate, peri-implant 
soft tissues and peri-implant crestal bone loss of implants inserted by flap or flapless surgery in type 2 controlled diabetic patients and immediately loaded with mandibular fixed prosthesis. The null hypothesis of the study was that there will be no significant difference in the studied outcomes between the 2 surgical approaches.

\section{MATERIALS AND METHODS}

\section{Patient enrollment and study design}

Twelve edentulous patients (6 males and 6 females, mean age of $58 \pm 4.6$ years) with controlled type II diabetes mellitus were selecting from the patients attending regularly at the outpatient clinic of the oral and maxillofacial department who had a desire to replace their missing teeth with fixed restoration. The inclusion criteria are; 1) Completely edentulous maxillary and mandibular ridges, 2) Patients medically diagnosed with type II-controlled diabetes (noninsulin dependent) with a history of well-controlled plasma glucose levels (fasting plasma glucose $\leq 140 \mathrm{mg} / \mathrm{dL}, 2$-hour postprandial glucose $\leq 200 \mathrm{mg} / \mathrm{dL}$ and glycosylated hemoglobin (HbA1c) from 5 to $6 \%$ ) as verified by patients' physicians and patients underwent oral hypoglycemic drugs, 3) patients had sufficient bone height and width (class III-V according to Cawood and Howell ${ }^{23}$ ) and density in anterior and posterior regions of the mandible to receive six implants of at least $11 \mathrm{~mm}$ in length and $3.7 \mathrm{~mm}$ in width. This was checked by preoperative cone beam computerized tomography (CBCT), and 4) Implant sites should had at least 4 months of healing following tooth extraction prior to implant placement The exclusion criteria include 1) patients with history of aggressive periodontitis, 2) Smokers, 3) patients with malignancy who underwent radiotherapy or chemotherapy, 4) patients with harmful habits such as clenching or bruxism, 5) bleeding disorders or other systemic diseases that may contraindicate implant surgery, 6) persons with a history of microvascular or macrovascular complications, and 7) patients with immunosuppressive drugs. Patients were informed about the steps of the study and the need for frequent recalls, then informed consents were obtained from participants. The study was conducted according to the ethical principles stated in the Helsinki Declaration and the study protocol was approved by the local ethical committee of the faculty of Dentistry. CONSORT guidelines for randomized controlled trials were followed.

Each patient was provided a number and entered into a spread Excel sheet. Using RAND command, the patients were randomly distributed. The patients were then randomly assigned into one of two groups using balanced randomization procedures to ensure equal age, and sex distribution between groups. Comparison of baseline criteria between groups was performed after randomization to ensure that there was no significant difference in age and sex between groups before the start of study. Randomization and allocation of participants was performed by blinded dentist. Group I (flap surgery) included six patients ( 3 males and 3 females) received 6 implants in the mandible using standardized full-thickness mucosal flap surgery and free hand implant placement, group II (flapless surgery) included six patients ( 3 males and 3 females) received 6 implants in the mandible using flapless surgical approach and computer guided implant placement. Implants in both groups will immediately loaded with provisional acrylic fixed restoration on the same day of surgery. Three months later, fixed porcelain fused to metal restoration we are delivered to all participants.

\section{Surgical and prosthetic protocol}

For both groups, maxillary and mandibular conventional dentures were constructed using the conventional steps of denture construction and bilateral balanced occlusal concept was used to enhance the stability of maxillary dentures. For both groups, 6 bone-level platform-switched implants (Tiologic, Dentarum, Germany) were 
planned to be inserted in the mandible (4 implants equally distributed in the interforaminal area and two implants posterior to the mental foramina). The implant diameters ranged from 3.7 to 4.8 and lengths ranged from 11 to $15 \mathrm{~mm}$ were installed. Implants were installed with at least $35 \mathrm{Ncm}$ insertion torque to provide good primary stability of the implants which is prerequisite for immediate loading ${ }^{24}$

Surgery was performed under local anesthesia for both groups. For flap group (Group I), gutta perchae radiopaque markers were attached to mandibular dentures at proposed implant sites to convert the denture to the radiographic template. Cone beam computerized tomography (CBCT, iCAT Vision, Hatfield, PA, USA) was performed while patients wearing the dentures to evaluate implant sites and the proximity of implants to vital structures. Moreover, CBCT was used to detect the proper implant length and diameter. The denture was then converted to surgical stent by attaching metal tubes at proposed implant sites. For flapless group (Group II), Radiopaque gutta perchae markers are added to the polished surface of the mandibular denture at labial, buccal and lingual flanges. Dual scan protocol was followed using cone beam CT (CBCT, i-CAT, Imaging Sciences International ISI, Pennsylvania, USA), Firstly, the patients were scanned while wearing their mandibular dentures, then the mandibular dentures were scanned alone. The two data sets of the double scans were overlapped then the acquired images were loaded into 3-D image treatment planning software (OnDemand). According to the CT scan, the implants were virtually planned, then an individualized stereolithographic surgical guide was constructed using prototyping technique (fig1). A mucosal supported stereolithographic surgical template with 6 sleeves positioned over proposed

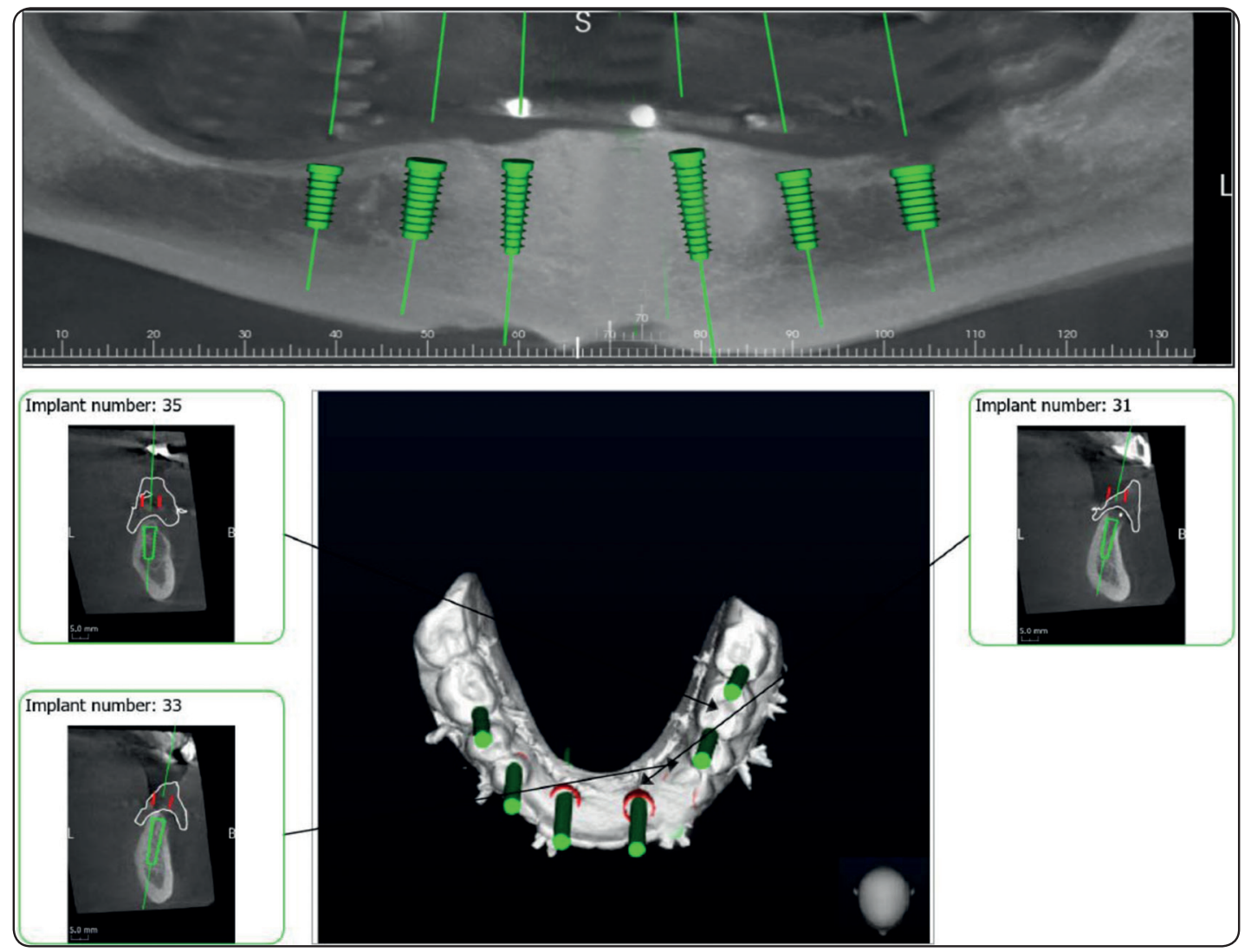

Fig. (1). Cone beam computerized tomography to evaluate implant sites, plane implant positions and construct sterolithographic guide 
implant sites was constructed using 3D printing technology (In2Guide).

For flap group, A mid crestal incision was made from first molar area on one side to first molar area on the other side. Then a full-thickness mucoperiosteal flap was raised. Using the surgical guide, 6 implants were inserted (4 implants equally distributed in the interforaminal area and two implants posterior to the mental foramina) parallel to each other's using successive drilling. Healing abutments were connected to the implants and the flap was closed with interrupted sutures interrupted sutures (Vicryl, 0000) (fig 2). For flapless group, implants were inserted according the flapless surgical protocol using mucosal supported stereolithographic surgical template and the universal surgical kit (In2Guide, Universal Kit Cybermed Inc) supplied with the template to be used during osteotomy preparation. This kit includes hand drill sleeves with successive increasing diameters that fit the template sleeves.
The mucosal supported template was stabilized in the patient's mouth by a rubber base interocclusal record and fixed to the mandibular bone using anchor pins. Implant osteotomies were prepared using successive drills of increased diameters that fit into metal sleeves of the template (fig 3). Postoperative panoramic radiograph was made to verify implant position (fig 4).

For both groups, Open tray impression was made on the implant level. Long transfer copings were threaded to the internal hex of the implants. A stock plastic tray was perforated over implant sites. Rubber dam sheets were adapted over the copings to protect the wound and the sutures during impression making. Orthodontic ligature wire was used to connect the transfer copings, then Duralay resin (Reliance, USA, with no dimensional changes) was adapted over the wire and the copings to splinted the transfer copings and to avoid movement of the impression copings during impression making (Fig

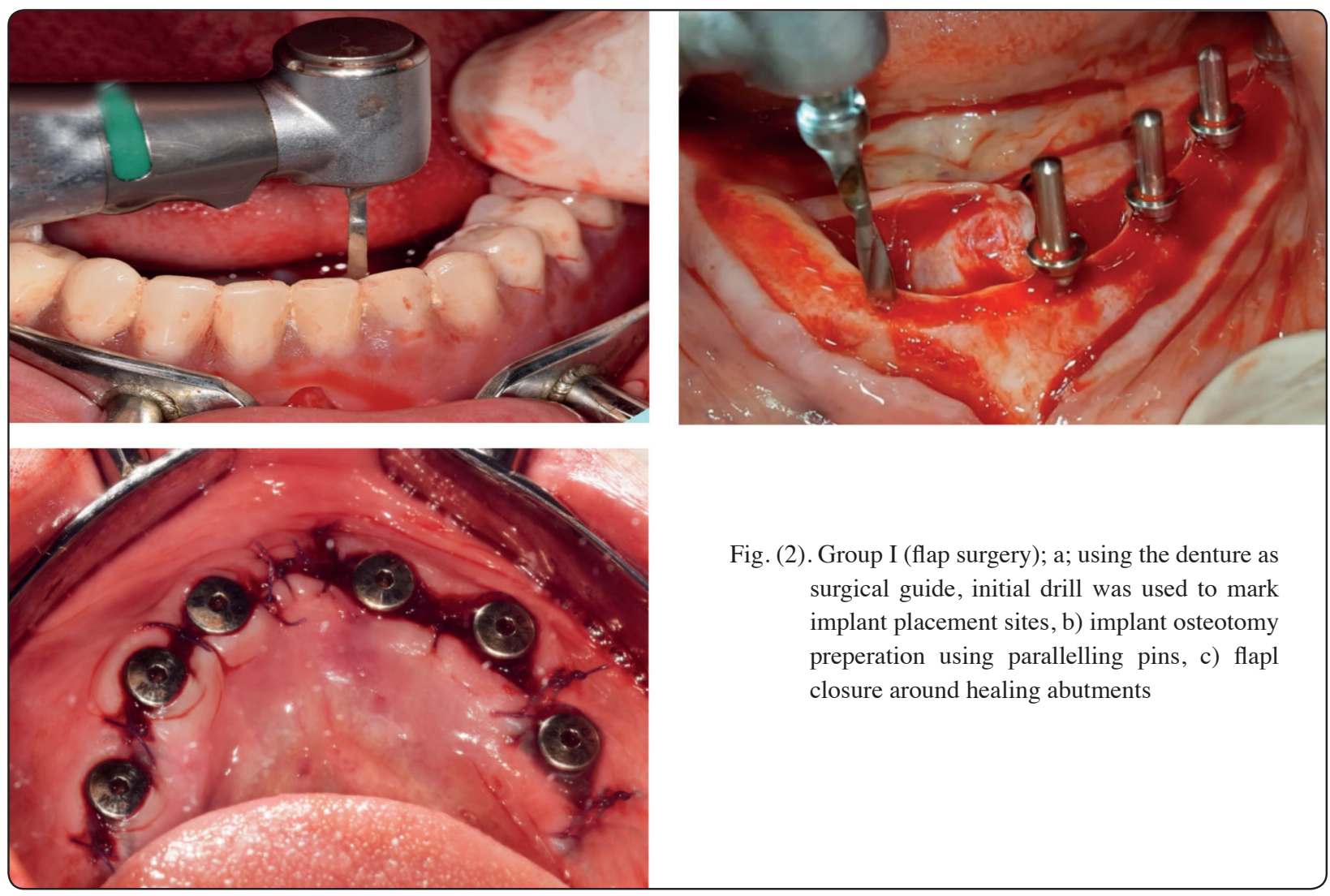



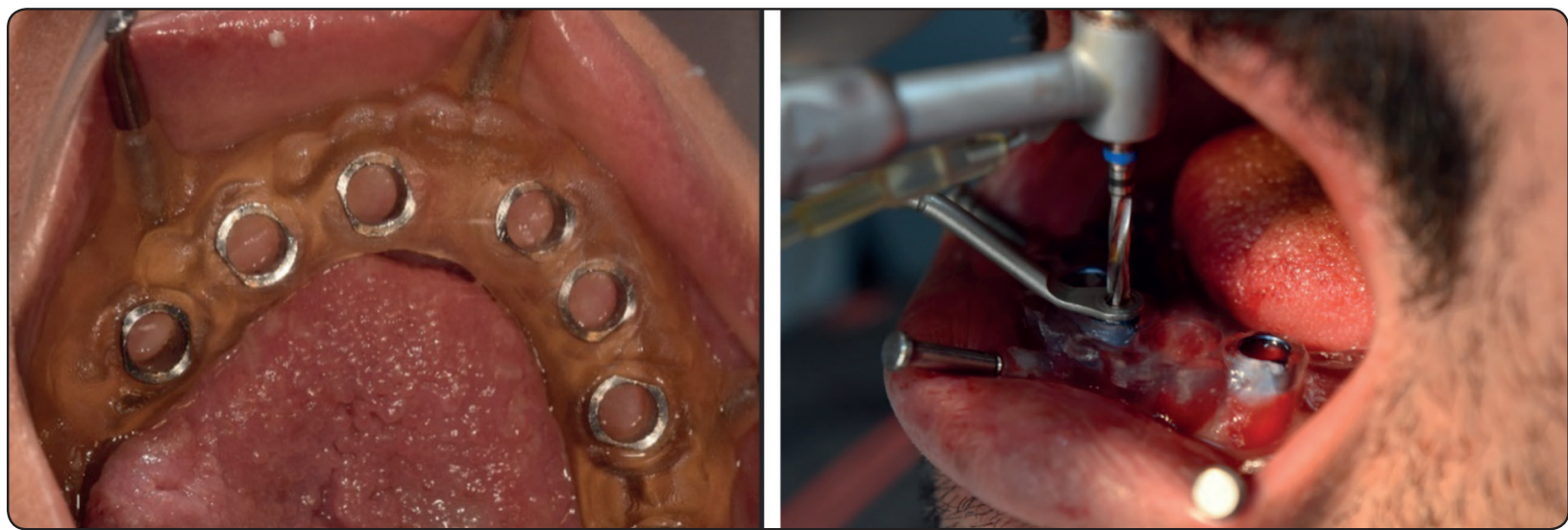

Fig. (3). Group II (flapless surgery); a; Mucosal supported sterolithographic surgical guide with metal sleeves fixed over implant positions and the guide is fixed to mandibular bone with fixation pins, b) preperation of implant osteotomy using In2Guide computer guided surgical kit

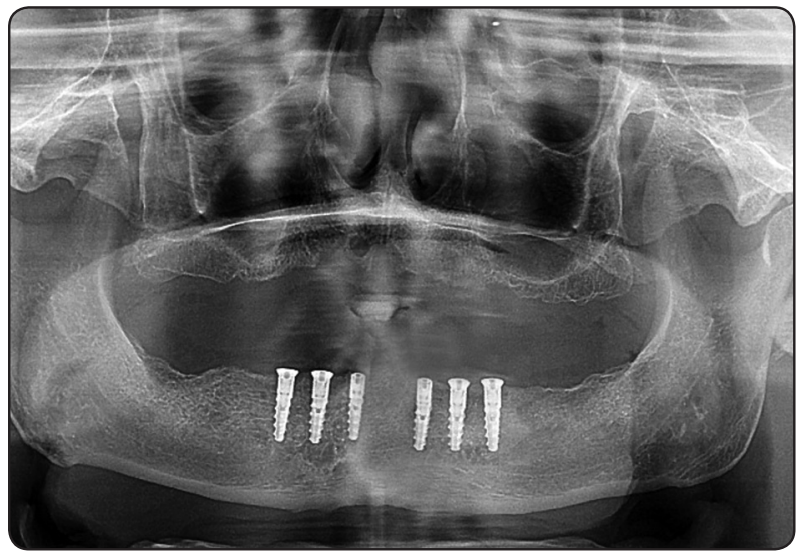

Fig. (4). Postoperative panoramic radiograph

5). Light body rubber base impression material was injected around the impression posts and the overall impression was completed using putty material (Zhermack®, Badia Polesine, Rovigo, Italy). Implant analogues were attached to the impression posts and the impression was poured using hard stone. Recorded bases were constructed record jaw relations and facial support. Straight titanium abutments were connected to the impression analogues, and fixed provisional screw retained tooth coloured acrylic resin was constructed in the laboratory. The prosthesis was screwed to the implants to allow immediate loading of the implants in the same day of surgery (fig 6).

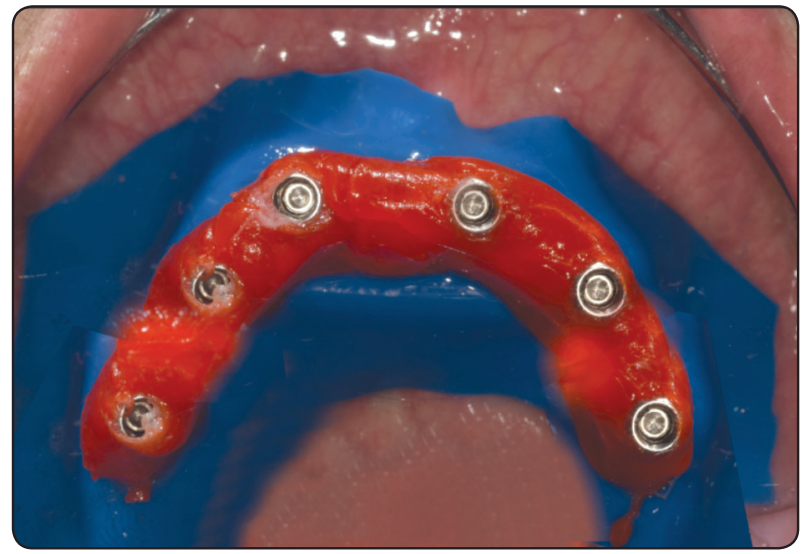

Fig. (5) Protection of the surgical site using the rubber dam and splinting of the transfer coping using Duralay resin

For both groups necessary occlusal adjustments were performed to ensure homogenous occlusal contact in centric and eccentric relations. Each patient was prescribed Antibiotics (amoxicillin and clavulanic acid (Augmentin 1gm/ twice daily) started before surgery and continued for 10 days postoperatively. Mouth wash (chlorhexidine digluconate $0.2 \%$ ) started before surgery and continued daily for 7 days postoperatively. Pain was controlled by analgesics (600 mg ibuprofen one every $8 \mathrm{~h}$ ) as long as needed. Also, Nonsteroidal anti-inflammatory drugs (Alphintern) were prescribed 3 times daily for 7 days. Instructions were given to the patient to use ice bags to reduce post operative edema. The 


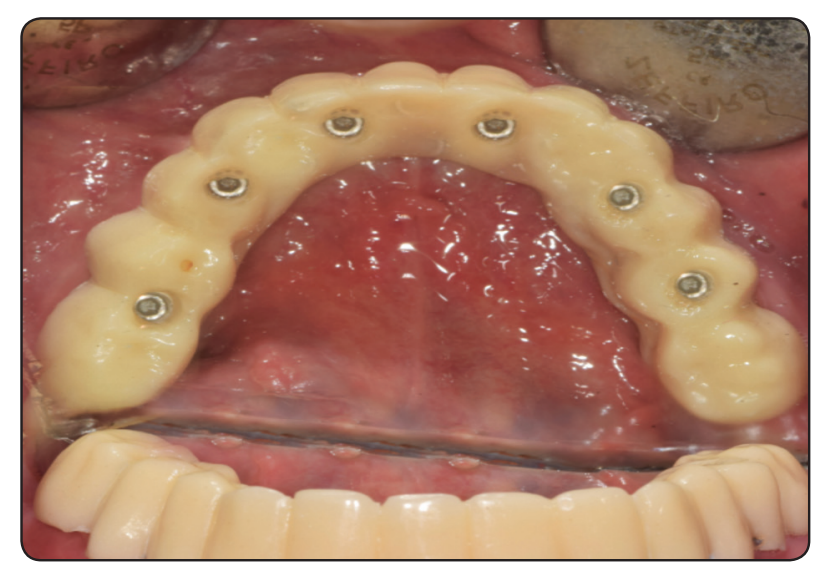

Fig. (6). Immediate loading of the implants with fixed provisional screw retained acrylic resin prosthesis

patients were instructed to eat soft diet and perform adequate oral hygiene. 3-months regular recall visits for data collection were scheduled for all participants over the study period.

Three months later (after osseointegration), the provisional acrylic prosthesis was unscrewed, then open tray impression was performed again to construct screw retained metal ceramic fixed prosthesis for both groups. On the resultant cast, Ti-base abutments (Tiologic) were threaded to the implant analogues and the cast was scanned using CAD/CAM device (Ceramill, Austria), then a fixed screw-retained hybrid prosthesis was designed with
12 teeth (from first molar on one side to first molar on the other side) then printed into castable resin and tried in patient mouth. The resin bridge was invested, cast with Cobalt chromium alloy, tried in for passive fit using single screw test. The porcelain powder (VITA, Germany) was mixed, applied onto the metal over the opaque layer, fired, finished and glazed. Pink porcelain was used to replace lost bone and gingival tissues when needed (fig 7). Fixed prostheses were delivered to all patients and panoramic radiographs were made to ensure passive seating of the prosthesis.

\section{Study outcomes}

Implant success rate was calculated using the criteria proposed by Albrektsson et al. ${ }^{25}$ which include; Absence of implant mobility; absence of pain, foreign body sensation and/or dysesthesia), absence of peri-implantitis and suppuration, absence of radiolucency around the implants and vertical bone loss was not exceed $1.5 \mathrm{~mm}$ in the first year. Implant was considered survived if it fulfills function, and does not require removal. Plaque index was measured according to Mombelli et al. ${ }^{26}$ and gingival index was measured using Loe and silness $^{27}$ Pocket depth was measured by plastic periodontal probe which inserted in the peri-implant sulcus to measure the distance between gingival

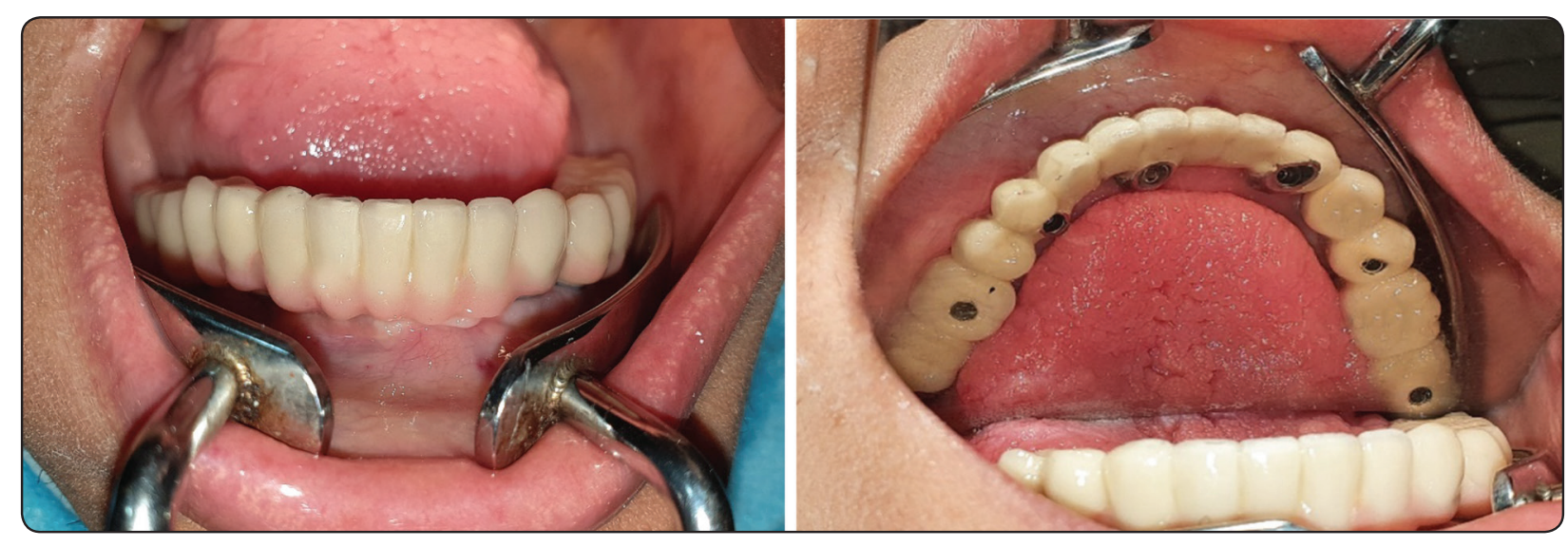

Fig. (7). Final metal ceramic screw retained hybrid prosthesis in place, a, buccal view, b) occlusal view 
margin and the most apical probing depth. Plaque index, Gingival Index, pocket depth were measured at mesial, distal, buccal, and lingual surface of each implant. The width of keratinized mucosa around each implant was measured in mm using a graduated periodontal probe as the distance between the gingival border to the muco-gingival junction on the buccal side of each implant ${ }^{28}$.

Crestal bone loss was measured at mesial, distal, buccal, and lingual surface of each implant using CBCT (i- CAT Vision, Hatfield, PA, USA). For standardization of exposure conditions, all images we are performed with the same acquisition time (14.7 second), voxel size and slice thickness. In the panoramic window of the CBCT software (OnDemand3DApp), marginal bone height was measured at mesial and distal surface of each implant. In the cross-sectional window of the CBCT software, marginal bone height was measured at buccal and lingual surface of each implant. To estimate marginal bone height at all surfaces, the distance from implant abutment junction (point A) to the bone contact with implant (point B) was measured using the ruler measure tool of the software to give bone level' ${ }^{29}$. Bone loss was calculated by evaluation of bone height changes from base line to 3 months, 6 months and 12 months. The mean marginal bone loss for all surfaces was used.

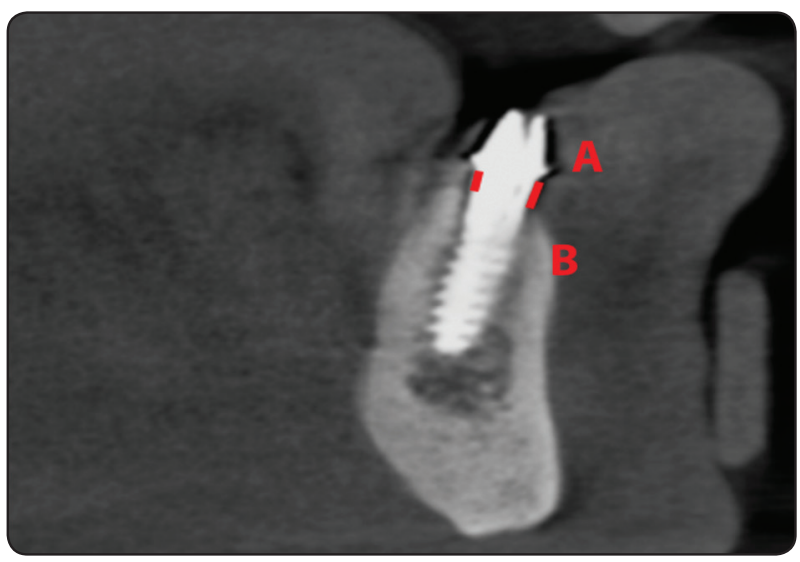

Fig. 8. Measurement of the crestal bone height at buccal and lingual surface of each implant in the cross-sectional images of the $\mathrm{CBCT}$
All clinical parameters were measured at immediate loading with provisional acrylic dentures (baseline), 3 months, 6 months, and 12 months after loading

\section{Statistical analysis}

Data was analyzed with SPSS program version 25. Shapiro wilk test of normality was used to evaluate normal distribution of the data. Kaplan Meier analysis and Log rank test were used to calculate implant survival rates. Friedman test, followed by Wilcoxon signed ranks tests were used to compare plaque and gingival indices between different time intervals and Mann- Whitney test was used to compare plaque and gingival indices between groups. Repeated measures ANOVA followed by Bonferroni test was used to compare pocket depth, implant stability, width of keratinized mucosa, and crestal bone loss between time intervals and groups. $\mathrm{P}$ is significant if it was less than $5 \%$.

\section{RESULTS}

In this study, the patients attended the regular follow-up and there were no dropouts. Two implants failed to integrate in the flap group (in 2 patients) and 3 implant failures (in 2 patients) occurred in the flapless group resulting in $94.5 \%$ and $91.6 \%$ implant survival rate in the flap and flapless groups respectively. Implant failures in both groups occurred within the first three months after implant loading with provisional acrylic restoration. No implant failures occurred later. The failed implants were occurred as a result of implant overloading and implants were associated with mobility, crestal bone loss, gingival inflammation and suppuration. The failed implants were removed and the remaining implants were used to support the final ceramometal prosthesis. The study was conducted according to intention to treat principal. Kaplan Meyer analysis of implant survival rate in both groups is presented in fig 9. There was no significant difference in implant survival rate between groups (log rank test, $\mathrm{p}=.652$ ). 


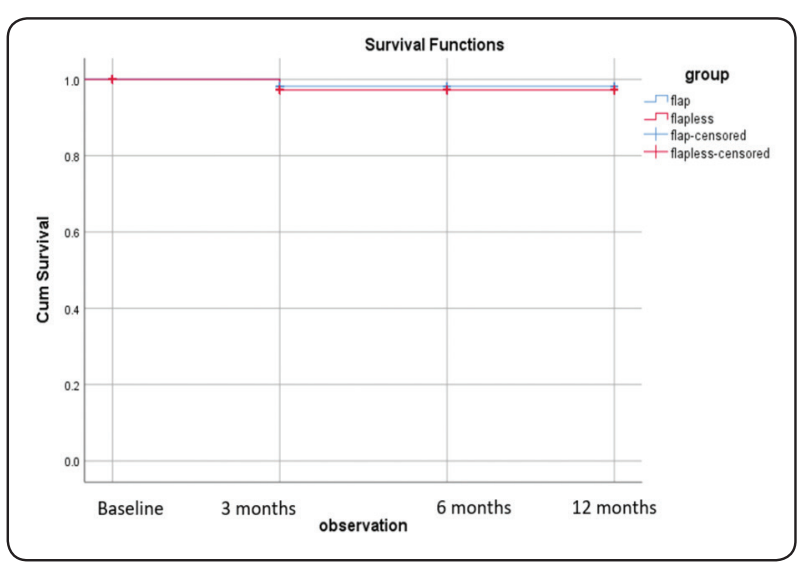

Fig. (9). Kaplan Meyer analysis of implant survival rate in both groups

Comparison of plaque and gingival scores between flap and flapless groups and between time intervals is presented in table 1. Plaque scores significantly differ between observation times for both groups ( $\mathrm{p}=.014$ and .031 for flap and flapless groups respectively). For both groups plaque scores significantly increased with time. Multiple comparison between each two observation times is presented in the same table. For flap group, there was a significant difference between each two observation times. For flapless group, no significant difference in plaque scores between 6 months and 12 months was observed. At baseline, no significant difference in plaque scores between groups was detected. At all other observation times, flap group showed significant higher plaque scores than flapless groups.

Gingival scores significantly differ between observation times for both groups $(\mathrm{p}=.032$ and .037 for flap and flapless groups respectively). For both groups gingival scores significantly increased from baseline to 3 months, then significantly decreased thereafter. Multiple comparison between each two observation times is presented in the same

TABLE (1) Comparison of plaque and gingival scores between flap and flapless groups and between time intervals

\begin{tabular}{|c|c|c|c|c|c|}
\hline & $\begin{array}{l}\text { Baseline Median } \\
\text { (Minimum- } \\
\text { maximum) }\end{array}$ & $\begin{array}{l}3 \text { month Median } \\
\text { (Minimum- } \\
\text { maximum) }\end{array}$ & $\begin{array}{l}6 \text { month Median } \\
\text { (Minimum- } \\
\text { maximum) }\end{array}$ & $\begin{array}{l}12 \text { month Median } \\
\text { (Minimum- } \\
\text { maximum) }\end{array}$ & $\begin{array}{r}\text { Freidman } \\
\text { (p value) }\end{array}$ \\
\hline & \multicolumn{5}{|c|}{ Medians of plaque scores } \\
\hline Flap group & $\begin{array}{c}.00 \mathrm{a} \\
(.00-.00)\end{array}$ & $\begin{array}{c}2.0 \mathrm{~b} \\
(1.0-3.0)\end{array}$ & $\begin{array}{c}1.50 \mathrm{c} \\
(1.5-2.0)\end{array}$ & $\begin{array}{c}1.40 \mathrm{~d} \\
(0.5-1.5)\end{array}$ & $.014 *$ \\
\hline Flapless group & $\begin{array}{c}.00 \mathrm{a} \\
(.00-.00)\end{array}$ & $\begin{array}{c}1.5 b \\
(1.00-2.0)\end{array}$ & $\begin{array}{c}1.1 \mathrm{c} \\
(0.6-1.4)\end{array}$ & $\begin{array}{c}1.20 \mathrm{c} \\
(1.00-1.5)\end{array}$ & $.031 *$ \\
\hline \multirow[t]{2}{*}{$\begin{array}{l}\text { Mann-Whitney } \\
\text { (p value) }\end{array}$} & 1.00 & $.018 *$ & $.021^{*}$ & $.040 *$ & \\
\hline & \multicolumn{5}{|c|}{ Medians of gingival scores } \\
\hline Flap group & $\begin{array}{c}.50 \mathrm{a} \\
(0.25-1.00)\end{array}$ & $\begin{array}{c}1.50 \mathrm{~b} \\
(1.00-2.00)\end{array}$ & $\begin{array}{c}1.00 \mathrm{c} \\
(.50-1.50)\end{array}$ & $\begin{array}{c}1.10 \mathrm{c} \\
(.60-1.5)\end{array}$ & $.032 *$ \\
\hline Flapless group & $\begin{array}{c}.10 \mathrm{a} \\
(.00-.40)\end{array}$ & $\begin{array}{c}1.00 \mathrm{~b} \\
(1.0-1.5)\end{array}$ & $\begin{array}{c}.60 c \\
(0.30-.80)\end{array}$ & $\begin{array}{c}0.50 c \\
(0.20-0.75)\end{array}$ & $.037 *$ \\
\hline $\begin{array}{l}\text { Mann-Whitney } \\
\text { (p value) }\end{array}$ & $.042 *$ & $.002 *$ & $.007 *$ & $.004 *$ & \\
\hline
\end{tabular}

${ }^{* p}$ is significant at .05 . Different small letters in the same raw show significant difference between time intervals (Wilcon test, $p<.05$ ), while similar letters show no difference 
table. For both groups, no significant difference in gingival scores was observed between 6 months and 12 months. For all observation times, flap group recorded significant higher gingival scores than flapless group.

Comparison of probing depth, keratinized mucosal width, and marginal bone loss between flap and flapless groups and between time intervals is presented in table 2. For both groups, there was a significant difference in pocket depth between observation times $(p=.013$, and .015 for flap and flapless group respectively). Pocket depth increased significantly with advance of time in both groups. Multiple comparisons of pocket depth between each two observation times are presented in the same table. For both groups there was a significant difference in pocket depth between each two observation times. At baseline, there was no significant difference in pocket depth between groups. For all other time intervals, flap group recorded significant higher pocket depth of the flapless group. Mean keratinized mucosal width significantly different between observation times for both groups. For flap group, keratinized mucosal width significantly increased from baseline to 3 months. For flapless group, keratinized mucosal width decreased insignificantly with time. For flap group, no significant difference in width of keratinized mucosa between 3 months, 6 months and 12 months was observed. There was a significant difference in mean marginal bone loss between observation times ( $\mathrm{p}=.001$ and .007 for flap and flapless group respectively). For both groups marginal bone loss significantly increased with time. Multiple comparison of marginal bone loss between each two observation times is presented in table 2. For both groups, there was a significant difference in marginal bone loss between each 2 time intervals. For observation times, flap group recorded significant higher marginal bone loss than flapless group.

TABLE (2) Comparison of probing depth, keratinized mucosal width, and marginal bone loss between flap and flapless groups and between time intervals

\begin{tabular}{|c|c|c|c|c|c|}
\hline & $\begin{array}{c}\text { Baseline mean } \pm \\
\text { standard deviation }\end{array}$ & $\begin{array}{c}3 \text { month mean } \pm \\
\text { standard deviation }\end{array}$ & $\begin{array}{c}6 \text { monthmean } \pm \\
\text { standard deviation }\end{array}$ & $\begin{array}{c}12 \text { monthmean } \pm \\
\text { standard deviation }\end{array}$ & $\begin{array}{c}\text { Repeated ANOVA } \\
\text { (p value) }\end{array}$ \\
\hline & \multicolumn{5}{|c|}{ Mean probing depth } \\
\hline Flap group & $1.12 \pm .35 \mathrm{a}$ & $1.32 \pm .27 \mathrm{~b}$ & $1.58 \pm .31 \mathrm{c}$ & $1.82 \pm .40 \mathrm{~d}$ & $.013 *$ \\
\hline Flapless group & $.91 \pm .29 \mathrm{a}$ & $1.00 \pm .29 \mathrm{~b}$ & $1.16 \pm .37 \mathrm{c}$ & $1.33 \pm .45 \mathrm{~d}$ & $.015^{*}$ \\
\hline \multirow[t]{2}{*}{ t-test (p value) } & .324 & $.024 *$ & $.003 *$ & $.004 *$ & \\
\hline & \multicolumn{5}{|c|}{ Mean Keratinized mucosal width } \\
\hline Flap group & $1.69 \pm .41 \mathrm{a}$ & $1.82 \pm .33 \mathrm{~b}$ & $1.81 \pm .38 \mathrm{~b}$ & $1.80 \pm .39 \mathrm{~b}$ & $.022 *$ \\
\hline Flapless group & $1.61 \pm .37 \mathrm{a}$ & $1.58 \pm .32 \mathrm{~b}$ & $1.56 \pm .33 b$ & $1.57 \pm .37 \mathrm{~b}$ & .058 \\
\hline \multirow[t]{2}{*}{ t-test (p value) } & .155 & $.005^{*}$ & $.002 *$ & $.001 *$ & \\
\hline & \multicolumn{5}{|c|}{ Mean marginal bone loss } \\
\hline Flap group & - & $0.62 \pm .12 \mathrm{a}$ & $.84 \pm .32 b$ & $1.2 \pm .33 \mathrm{c}$ & $<.001 *$ \\
\hline Flapless group & - & $0.40 \pm .13 \mathrm{a}$ & $0.63 \pm .24 b$ & $.91 \pm .33 \mathrm{c}$ & $.007 *$ \\
\hline t-test (p value) & & $.011 *$ & $.014 *$ & $.005^{*}$ & \\
\hline
\end{tabular}

*p is significant at .05. Different small letters in the same raw show significant difference between time intervals (Bonferroni test, $p<.05)$, while similar letters show no difference 


\section{DISCUSSION}

Three-Dimensional cone beam computerized tomography was used for evaluation of crestal bone height changes around implants as it provides information about buccal and lingual bone resorption in addition to mesial and distal bone resorption was which is not provided by the twodimensional periapical radiography ${ }^{30,31}$. Also Cone beam CT is easily used with edentulous patients had elevated floor of the mouth which makes periapical radiographs difficult to perform ${ }^{30,31}$. The use of cone beam CT in evaluation of marginal bone resorption around implants was previously described in other studies ${ }^{29,32}$

The implant survival rate was $94.5 \%$ and $91.6 \%$ in the flap and flapless groups respectively without difference between groups. Similarly, Agrawal et al. ${ }^{10}$ found a similar survival rate for implants inserted with flap (95.7\%) and flapless (93.5\%) surgical approaches and conventionally loaded in controlled diabetic patients. They also found no significant difference in implant survival rate between flap and flapless groups. The high survival rate in both groups could be attributed to the good bone density in the mandible which provide higher implant stability that can withstand micromotions of immediate loading. Another explanation could be attributed to the good glycemic control in the included participants patients

In this study, plaque and gingival scores increased significantly with time in both groups. The large median plaque and gingival scores obtained after 3 months in both groups. This could be attributed to the presence of provisional acrylic bridge which have spaces around the implants that may hinder adequate cleaning by the patients. When professional restoration was replaced by ceramometal restoration, plaque scores decreased after six months due to the smooth convex surface of prosthesis and the high adaptation of the prosthesis to the abutments. The increased gingival scores after 3 months are attributed to the increased plaque scores which cause gingival inflammation. The increased plaque and gingival scores was in line with Peled et al. ${ }^{33}$ who observed plaque accumulation and periimplant gingivitis in controlled type II diabetic patients with advance of time. Decreased plaque scores after six months were similar to finding of another study ${ }^{34}$ in which a significant decrease in plaque around implants supporting fixed immediate prostheses was noted after 6 months. The increased plaque and gingival index with advance of time for flap and flapless groups was in line with finding of another study ${ }^{10}$ in which the authors reported a progressive increase of plaque index in sulcular bleeding index after one year. The flap group recorded significant higher plaque and gingival index than flapless group. In agreement with this finding, Agrawal et al..$^{5}$ reported that flap group had significant increase of plaque index and the mean sulcular bleeding index compared to the flapless group when implants are conventionally loaded in controlled diabetic patients. Al-Amiri et al. ${ }^{21}$ found no significant difference in plaque and bleeding index between conventionally loaded and immediate loaded single implants inserted in controlled type II diabetic patients. The increased plaque and gingival scores in the flap group may be attributed to the flap surgery which discourage the patients to perform adequate cleaning to avoid pain in the surgical site. Even after healing the wound, they develop the habit of avoiding cleaning to avoid discomfort. The increased plaque scores could be responsible for increased gingival scores in the flap group due to peri-implant mucosal inflammation.

Pocket depth significantly increased with advance of time in both groups. This may reflect the increased marginal bone loss combined with gingival overgrowth that occurred in both groups. In agreement with this observation, Agrawal et al. ${ }^{5}$ reported significant increase in peri-implant probing depth in both flap and flapless groups when implants are conventionally loaded in controlled diabetic patients. In contrast, Kapur, et al. ${ }^{35}$ showed no significant change in pocket depth with passage 
of time around implants supporting mandibular overdentures in patients with controlled diabetes. The flap group recorded significant higher pocket depth than flapless group at all observation times. The increased pocket depth with flap group could be attributed to peri-implant gingival enlargement caused by flap reflection, re-adaptation and suturing the flap over the abutments together with increased peri-implant bone loss in the flap group compared to flapless group ${ }^{36}$. On the other hand, the flapless approach provides gap free connection with optimum mucosal barrier free of bacterial accumulation that may protect soft tissue and allow establishment of a tissue collar overlapping the bone implant interface with decreased pocket depth ${ }^{37}$. The increased pocket depth with computer guided flapless approach concurred with the findings of another study. ${ }^{38}$

Keratinized mucosal width significantly increased from baseline to 3 months for flap group and insignificantly decreased for flapless group. Also flap group reported significant increase in the width of keratinized mucosa than flapless group. The increased keratinized mucosal width in the flap group could be attributed to the crestal incision and mucosal reflection and readaptation of the flap around the abutments to be in a more apical position. This brings the keratinized mucosa which present on the crest of the ridge to a more apical position similar to apical positioned flap which help in increase the width of keratinized mucosa ${ }^{39}$. The increase width of keratinized mucosa with flap surgery concurred with the results of other studies ${ }^{18,19,40}$. The insignificant decrease in the width of keratinized mucosa for flapless group concurred with the results of Wang et al.$^{40}$ who reported limited reduction of keratinized mucosal width with stable keratinized mucosa when minimal invasive flapless surgical approach was used for single implant placement in non-diabetic patients.

For both groups, crestal bone loss significantly increased with time. This time dependent upon loss is usually occur as a result of one the healing, bone maturation and bone reaction to increased load $^{41}$. Moreover, the immediate loading of the implants with acrylic prosthesis may increase implant micromotions and could be responsible for increased bone resorption in both groups ${ }^{42}$. It has been proposed that diabetes leads to decreased bone turnover, with reductions in both resorption and formation ${ }^{43}$. However, the mean marginal bone loss after one year for both groups did not exceed $1.2 \mathrm{~mm}$ which located within the normal limit of marginal bone loss reported to occur in the first year for nondiabetic patients ${ }^{25}$. This suggests that influence of diabetes on bone and osteoblast function was shown to improve by good glycaemic control ${ }^{44}$. Furthermore, the high initial stability of the implants caused by increased bone density in mandibular bone together with splinting the implants with rigid fixed restoration could be responsible for maintaining the bone loss values within the normal limits. Another factor that could contribute to the high survival rate of the implants in both groups and the reduced bone loss is the status of opposing occlusion. The factors that opposing prosthesis was complete dentures in both groups may reduce the impact of occlusal forces to the mandibular fixed prosthesis and could contribute to reduced bone loss.

Flap group showed significant higher crestal bone loss than flapless group. The increased crestal bone loss in the flap group may be attributed to flap elevation, microbial contamination, mucosal stripping, and interferences with blood supply to mucoperiosteum caused by flap reflection compared to flap surgery ${ }^{45-47}$. The decreased blood supply to the mucoperiosteum may decrease oxygen tension and activities osteoclastic activity leading to increase the implant crestal bone $\operatorname{loss}^{45-47}$. In contrast, flapless surgery reduces surgical time, reduces the need of sutures, reduces postoperative swelling and discomfort. On the other hand, the flapless procedure reduced surgical time, have no sutures, minor or no swelling, with minimal postoperative discomfort ${ }^{48}$. Moreover, the mucoperiosteum is not disturbed which may enhance bone remodeling, 
with slight changes in marginal bone levels compared with flap surgery ${ }^{48}$. In agreement with our finding, systematic review reported that flapless cortical better short term clinical and radiographic outcomes compared to flap surgery for non-diabetic patients $^{49}$. Conversely, another study ${ }^{22}$ found no difference in marginal bone loss between flap and flapless surgical approach for conventionally loaded implants in controlled diabetic patients. The difference in the results would be attributed to the different loading protocol used in each study.

The limitations of the present study include the small patient sample size and short follow-up period. Randomized controlled trials with large patient sample and the longer follow up period are still needed to confirm the findings of this study. Also studying different opposing occlusion such as natural teeth or fixed partial dentures still need to be investigated

\section{CONCLUSION}

Within the limitation of this short-term randomized trial, computer guided flapless surgical approach may be recommended for implants placed in edentulous type 2 controlled diabetic patients and immediately loaded with mandibular fixed prosthesis as it was associated with favorable peri-implant soft tissue response and crestal bone loss compared to implants placed with flap surgery after one year.

\section{REFERENCES}

1. Danaei G, Finucane MM, Lu Y, Singh GM, Cowan MJ, Paciorek CJ, Lin JK, Farzadfar F, Khang YH, Stevens GA, Rao M, Ali MK, Riley LM, Robinson CA, Ezzati M. National, regional, and global trends in fasting plasma glucose and diabetes prevalence since 1980: systematic analysis of health examination surveys and epidemiological studies with 370 country-years and 2.7 million participants. Lancet 2011; 378: 31-40.

2. Mellado-Valero A, Ferrer Garcia JC, Herrera Ballester A, Labaig Rueda C. Effects of diabetes on the osseointegration of dental implants. Med Oral Patol Oral Cir Bucal 2007; 12: E38-43.
3. Farzad P, Andersson L, Nyberg J. Dental implant treatment in diabetic patients. Implant Dent 2002; 11: 262-267.

4. Kotsovilis S, Karoussis IK, Fourmousis I. Acomprehensive and critical review of dental implant placement in diabetic animals and patients. Clin Oral Implants Res 2006; 17: 587-599.

5. Al Amri MD, Kellesarian SV, Al-Kheraif AA, Malmstrom H, Javed F, Romanos GE. Effect of oral hygiene maintenance on $\mathrm{HbA} 1 \mathrm{c}$ levels and peri-implant parameters around immediately-loaded dental implants placed in type2 diabetic patients: 2 years follow-up. Clin Oral Implants Res 2016; 27: 1439-1443.

6. Oates TW, Jr., Galloway P, Alexander P, Vargas Green A, Huynh-Ba G, Feine J, McMahan CA. The effects of elevated hemoglobin $\mathrm{A}(1 \mathrm{c})$ in patients with type 2 diabetes mellitus on dental implants: Survival and stability at one year. J Am Dent Assoc 2014; 145: 1218-1226.

7. Aguilar-Salvatierra A, Calvo-Guirado JL, GonzalezJaranay M, Moreu G, Delgado-Ruiz RA, Gomez-Moreno G. Peri-implant evaluation of immediately loaded implants placed in esthetic zone in patients with diabetes mellitus type 2: a two-year study. Clin Oral Implants Res 2016; 27: $156-161$.

8. Rodbard HW, Jellinger PS, Davidson JA, Einhorn D, Garber AJ, Grunberger G, Handelsman Y, Horton ES, Lebovitz H, Levy P, Moghissi ES, Schwartz SS. Statement by an American Association of Clinical Endocrinologists/ American College of Endocrinology consensus panel on type 2 diabetes mellitus: an algorithm for glycemic control. Endocr Pract 2009; 15: 540-559.

9. American Diabetes Association: Standards of medical care in diabetes--2010. Diabetes Care 2010; 33 Suppl 1: S11-61.

10. Agrawal KK, Rao J, Anwar M, Singh K, Himanshu D. Flapless vs flapped implant insertion in patients with controlled type 2 diabetes subjected to delayed loading: 1-year follow-up results from a randomised controlled trial. Eur J Oral Implantol 2017; 10: 403-413.

11. Naujokat H, Kunzendorf B, Wiltfang J. Dental implants and diabetes mellitus-a systematic review. Int J Implant Dent 2016; $2: 5$.

12. Oates TW, Huynh-Ba G, Vargas A, Alexander P, Feine J. A critical review of diabetes, glycemic control, and dental implant therapy. Clin Oral Implants Res 2013; 24:117-127. 
13. Wadhwa B, Jain V, Bhutia O, Bhalla AS, Pruthi G. Flapless versus open flap techniques of implant placement: A 15-month follow-up study. Indian J Dent Res 2015; 26: 372-377.

14. Al-Khabbaz AK, Griffin TJ, Al-Shammari KF. Assessment of pain associated with the surgical placement of dental implants. J Periodontol 2007; 78: 239-246.

15. Chrcanovic BR, Albrektsson T, Wennerberg A. Flapless versus conventional flapped dental implant surgery: a meta-analysis. PLoS One 2014; 9: e100624.

16. Rousseau P. Flapless and traditional dental implant surgery: an open, retrospective comparative study. J Oral Maxillofac Surg 2010; 68: 2299-2306.

17. Brodala N. Flapless surgery and its effect on dental implant outcomes. Int J Oral Maxillofac Implants 2009; 24 Suppl: 118-125.

18. Cannizzaro G, Leone M, Consolo U, Ferri V, Esposito M. Immediate functional loading of implants placed with flapless surgery versus conventional implants in partially edentulous patients: a 3-year randomized controlled clinical trial. Int J Oral Maxillofac Implants 2008; 23: 867-875.

19. Cannizzaro G, Felice P, Leone M, Checchi V, Esposito M. Flapless versus open flap implant surgery in partially edentulous patients subjected to immediate loading: 1-year results from a split-mouth randomised controlled trial. Eur J Oral Implantol 2011; 4: 177-188.

20. Romanos GE, Nentwig GH. Immediate versus delayed functional loading of implants in the posterior mandible: a 2-year prospective clinical study of 12 consecutive cases. Int J Periodontics Restorative Dent 2006; 26: 459-469.

21. Al Amri MD, Alfarraj Aldosari AM, Al-Johany SS, Al Baker AM, Al Rifaiy MQ, Al-Kheraif AA. Comparison of clinical and radiographic status around immediately loaded versus conventional loaded implants placed in patients with type 2 diabetes: 12 - and 24-month follow-up results. J Oral Rehabil 2017; 44: 220-228.

22. Yadav R, Agrawal KK, Rao J, Anwar M, Alvi HA, Singh K, Himanshu D. Crestal Bone Loss under Delayed Loading of Full Thickness Versus Flapless Surgically Placed Dental Implants in Controlled Type 2 Diabetic Patients: A Parallel Group Randomized Clinical Trial. J Prosthodont 2018; 27: 611-617.

23. Cawood JI, Howell RA. A classification of the edentulous jaws. Int J Oral Maxillofac Surg 1988; 17: 232-236.
24. Sannino G, Bollero P, Barlattani A, Gherlone E. A Retrospective 2-Year Clinical Study of Immediate Prosthetic Rehabilitation of Edentulous Jaws with Four Implants and Prefabricated Bars. J Prosthodont 2017; 26: 387-394.

25. Albrektsson T, Zarb G, Worthington P, Eriksson AR. The long-term efficacy of currently used dental implants: a review and proposed criteria of success. Int $\mathrm{J}$ Oral Maxillofac Implants 1986; 1: 11-25.

26. Mombelli A, van Oosten MA, Schurch E, Jr., Land NP. The microbiota associated with successful or failing osseointegrated titanium implants. Oral Microbiol Immunol 1987; 2: 145-151.

27. Loe H, Silness J. Periodontal Disease in Pregnancy. I. Prevalence and Severity. Acta Odontol Scand 1963; 21: 533-551.

28. Lin GH, Chan HL, Wang HL. The significance of keratinized mucosa on implant health: a systematic review. J Periodontol 2013; 84: 1755-1767.

29. Elsyad MA, Khirallah AS. Circumferential bone loss around splinted and nonsplinted immediately loaded implants retaining mandibular overdentures: A randomized controlled clinical trial using cone beam computed tomography. J Prosthet Dent 2016; 116 741-748

30. Naitoh M, Hayashi H, Tsukamoto N, Ariji E. Labial bone assessment surrounding dental implant using conebeam computed tomography: an in vitro study. Clin Oral Implants Res 2012; 23: 970-974.

31. Raes F, Renckens L, Aps J, Cosyn J, De Bruyn H. Reliability of circumferential bone level assessment around single implants in healed ridges and extraction sockets using cone beam CT. Clin Implant Dent Relat Res 2013; 15: 661-672.

32. Razavi T, Palmer RM, Davies J, Wilson R, Palmer PJ. Accuracy of measuring the cortical bone thickness adjacent to dental implants using cone beam computed tomography. Clin Oral Implants Res 2010; 21: 718-725.

33. Peled M, Ardekian L, Tagger-Green N, Gutmacher Z, Machtei EE. Dental implants in patients with type 2 diabetes mellitus: a clinical study. Implant Dent 2003; 12: 116-122.

34. Ayub KV, Ayub EA, Lins do Valle A, Bonfante G, Pegoraro T, Fernando L. Seven-Year Follow-up of Full-Arch Prostheses Supported by Four Implants: A Prospective Study. The International journal of oral \& maxillofacial implants 2017; 32: 1351-1358. 
35. Kapur KK, Garrett NR, Hamada MO, Roumanas ED, Freymiller E, Han T, Diener RM, Levin S, Ida R. A randomized clinical trial comparing the efficacy of mandibular implant-supported overdentures and conventional dentures in diabetic patients. Part I: Methodology and clinical outcomes. J Prosthet Dent 1998; 79: 555-569.

36. ELsyad MA, Denewar BA, Elsaih EA. Clinical and Radiographic Evaluation of Bar, Telescopic, and Locator Attachments for Implant-Stabilized Overdentures in Patients with Mandibular Atrophied Ridges: A Randomized Controlled Clinical Trial. The International journal of oral \& maxillofacial implants 2018; 33: 1103-1111.

37. Omran M, Abdelhamid A, Elkarargy A., Sallom M. MiniImplant Overdenture Versus Conventional Implant Overdenture (A Radiographic and ClinicalAssessments). 2013; 9: 89-97.

38. Malo P, de Araujo Nobre M, Lopes A. The use of computerguided flapless implant surgery and four implants placed in immediate function to support a fixed denture: preliminary results after a mean follow-up period of thirteen months. J Prosthet Dent 2007; 97: S26-34.

39. Bassetti RG, Stahli A, Bassetti MA, Sculean A. Soft tissue augmentation around osseointegrated and uncovered dental implants: a systematic review. Clin Oral Investig 2017; 21: 53-70.

40. Wang F, Huang W, Zhang Z, Wang H, Monje A, Wu Y. Minimally invasive flapless vs. flapped approach for single implant placement: a 2-year randomized controlled clinical trial. Clin Oral Implants Res 2017; 28: 757-764.

41. Hekimoglu C, Anil N, Cehreli MC. Analysis of strain around endosseous dental implants opposing natural teeth or implants. J Prosthet Dent 2004; 92: 441-446.
42. De Smet E, Duyck J, Vander Sloten J, Jacobs R, Naert I. Timing of loading--immediate, early, or delayed--in the outcome of implants in the edentulous mandible: a prospective clinical trial. Int J Oral Maxillofac Implants 2007; 22: 580-594.

43. Krakauer JC, McKenna MJ, Buderer NF, Rao DS, Whitehouse FW, Parfitt AM. Bone loss and bone turnover in diabetes. Diabetes 1995; 44: 775-782.

44. Casap N, Nimri S, Ziv E, Sela J, Samuni Y. Type 2 diabetes has minimal effect on osseointegration of titanium implants in Psammomys obesus. Clin Oral Implants Res 2008; 19: 458-464.

45. Ahn MR, An KM, Choi JH, Sohn DS. Immediate loading with mini dental implants in the fully edentulous mandible. Implant Dent 2004; 13: 367-372.

46. Bulard RA, Vance JB. Multi-clinic evaluation using minidental implants for long-term denture stabilization: a preliminary biometric evaluation. Compend Contin Educ Dent 2005; 26: 892-897.

47. Jeong SM, Choi BH, Li J, Kim HS, Ko CY, Jung JH, Lee HJ, Lee SH, Engelke W. Flapless implant surgery: an experimental study. Oral Surg Oral Med Oral Pathol Oral Radiol Endod 2007; 104: 24-28.

48. Tsoukaki M, Kalpidis CD, Sakellari D, Tsalikis L, Mikrogiorgis G, Konstantinidis A. Clinical, radiographic, microbiological, and immunological outcomes of flapped vs. flapless dental implants: a prospective randomized controlled clinical trial. Clin Oral Implants Res 2013; 24: 969-976.

49. Llamas-Monteagudo O, Girbes-Ballester P, Vina-Almunia J, Penarrocha-Oltra D, Penarrocha-Diago M. Clinical parameters of implants placed in healed sites using flapped and flapless techniques: A systematic review. Med Oral Patol Oral Cir Bucal 2017; 22: e572-e581. 